\title{
Regional Patterns of the Temporal Evolution of the AIDS Epidemic in Brazil Following the Introduction of Antiretroviral Therapy
}

\author{
Ana Maria de Brito ${ }^{1,2}$, Euclides Ayres de Castilho ${ }^{3}$ \\ and Célia Landmann Szwarcwald ${ }^{4}$
}

\author{
Department of Social Medicine, School of Medical \\ Science, University of Pernambuco ${ }^{1}$; Aggeu Magalhães \\ Research Center, Oswaldo Cruz Foundation ${ }^{2}$,Recife, \\ PE; Department of Preventive Medicine, School of \\ Medicine, University of São Paulo ${ }^{3}$, São Paulo, SP; \\ Scientific and Technological Information Center, \\ Oswaldo Cruz Foundation ${ }^{4}$, Rio de Janeiro, RJ, Brazil.
}

\begin{abstract}
We examined the characteristics of the AIDS epidemic in the northeastern region of Brazil, comparing it to the epidemic in Brazil as a whole, and to the state of São Paulo, with respect to the temporal evolution of morbidity and mortality during the period 1990 to 1999, using information from communicable disease reports and mortality records. Since 1996, the incidence rate of AIDS in adults in Brazil as a whole and in São Paulo has been showing a trend towards stability, whereas in the Brazilian northeast the incidence rates of the disease continue to grow. In the northeast, sexual transmission is responsible for more than $80 \%$ of cases, injectable drug users (IDU) comprising only a small percentage of cases. There is a greater incidence of AIDS among groups with lower educational levels throughout the country. The comparative analysis of cases of AIDS and of deaths from AIDS shows growth, both in the number of cases and in the number of deaths; however, from 1996 onwards there has been a progressive reduction in the number of deaths in all regions analyzed. With respect to the incidence of cases of the disease acquired by vertical transmission, a significant growth trend can be seen in all regions for cases born in the period 1990-6, but in 1997 temporal analysis showed evidence of a reduction in this growth. In conclusion, temporal changes have occurred in the AIDS epidemic in Brazil, which has been showing a trend towards stability since 1996, when potent ARV therapy was introduced. However, this deceleration is not homogenous throughout all the regions.

Key Words: AIDS, morbidity/mortality, temporal trend, antiretroviral therapy, Brazil, northeastern region.
\end{abstract}

The AIDS epidemic constitutes a dynamic and diversified global phenomenon, whose profile in the various regions of the world depends, among other factors, on individual and collective human behavior, on the period when the virus was introduced, on the principal means of transmission and on the control measures adopted.

Received on 30 September 2004; revised 12 January 2005. Address for correspondence: Dr. Euclides Ayres de Castilho. Faculdade de Medicina, Universidade de São Paulo. Av. Dr. Arnaldo 455, Zip code: 01246-903, São Paulo, SP, Brazil. E-mail: castil@usp.br

The Brazilian Journal of Infectious Diseases 2005;9(1):9-19 (C) 2005 by The Brazilian Journal of Infectious Diseases and Contexto Publishing. All rights reserved.
The accumulation of knowledge on the etiology and pathogenesis of infection by the human immunodeficiency virus (HIV), together with technological advances, has made new, more efficient, diagnostic, prophylactic and therapeutic options possible that have altered the natural history of AIDS [1]. In recent years, the widespread use of highly effective and potent antiretroviral therapy has significantly increased the quality of life of AIDS victims and has caused a change in the profile of the epidemic.

Up to the end of the 1980s, the therapeutic management of patients with AIDS was limited to the treatment of opportunistic infections. Nowadays, specific treatment has contributed towards a change in 
the morbidity/mortality profile, principally from 1996 onwards, when combined antiretroviral (ARV) therapy was introduced, made possible by the development of the non-nucleoside analogs and protease inhibitors [2-4].

In developed countries, the trend towards a reduction in AIDS-related mortality and morbidity had already been observed prior to the introduction of potent anti-HIV therapy, and it had been attributed to the prophylactic treatment of opportunistic infections. The arrival of the protease inhibitors accentuated these reductions [5]. Following the introduction of potent ARV therapy, an important decrease was observed in the occurrence of opportunistic infections, a reduction in hospital admissions and in deaths, as well as a significant increase in the survival rates of AIDS sufferers in Europe, in the US and in Canada [6-10]. The mean life expectancy of a person who became infected with HIV between 1996 and 1999 and who had access to ARV medication is estimated at 20 years [11].

In Brazil, strategies for the treatment of HIV infection and AIDS date from the 1980s, and there are records of the use of medications for opportunistic infections in the National Health Service in 1988 [12]. Antiretroviral therapy became available within the National Health Service in 1991 and in 1996 approximately 20,000 patients received treatment. From that year onwards, ARV therapy became more widespread. In 2001, around 105,000 people were receiving treatment with 15 different $A R V$ medications distributed by the National Health Service (SUS) [13]. It should be emphasized that Brazil was the first developing country to adopt a policy of distributing antiretroviral medication free of charge throughout the country.

According to the Ministry of Health, these initiatives have created an impact similar to that seen in developed countries, in terms of the reduction in the deaths caused by AIDS, the occurrence of opportunistic infections and hospital admissions [14]. A reduction of more than $20 \%$ was seen in the use of some medications for opportunistic infections, such as cytomegalovirus [12], and a recent study showed a significant change in the median survival of patients over 12 years of age between the period 1982 to 1999 and the period 1995 to 1996. In the first period, median survival was 5.1 months following AIDS diagnosis, whereas in 1995 mean survival was 16 months, and those diagnosed in 1996 had an extremely significant increase in survival to 58 months [15].

Studies on the dynamics of the AIDS epidemic in Brazil show that the epidemic has been tending to stabilize from 1997 onwards [12]. However, this trend does not appear to be homogenic throughout all the regions of the country or in all subgroups of the population. In Brazil, studies predominantly refer to populations in the south and southeast of the country, justified by the size of the epidemic and by the diversity of the forms of HIV dissemination in these areas. Therefore, characterizing the AIDS epidemic in the northeastern states, a region in which a relatively low frequency of AIDS cases is registered, is important because of the greater possibility for control in this region before the disease reaches the epidemic proportions that are prevalent in other regions of the country.

Our objective was to characterize the AIDS epidemic in the northeastern region of Brazil and to compare it to the country as a whole and to the state of São Paulo, particularly with respect to the temporal evolution of morbidity/mortality following the introduction of antiretroviral therapy.

\section{Material and Methods}

Data from communicable disease reports (Sistema de Informação de Agravos de Notificação SINAN) were used to obtain information on cases of AIDS, while information on deaths was obtained from the death registry (Sistema de Informação sobre Mortilidade-SIM), (http://www.datasus.gov.br).

To calculate the incidence coefficient according to gender and geographic region, cases of AIDS communicated to the National Program of STDs and AIDS up to December 2002 were used, where the age of the patient was $\geq 13$ years and the date of diagnosis was between 1990 and 1999, and the annual resident population was estimated according to data 
from the demographic censuses and inter-census projections carried out by the Brazilian Institute of Geography and Statistics (IBGE), (http:// www.ibge.gov.br). For the purpose of this analysis, the last year of diagnosis considered was 1999. This cutoff date was selected with the intention of reducing the bias introduced into the analysis by the temporal trend of delaying notification of cases.

For the analysis of the temporal evolution of the epidemic according to the principal means of HIV transmission, we analyzed the proportions of cases according to the subcategories of exposure and according to the information registered on the clinical record of investigation/notification of AIDS. The variable "type of exposure" was divided into six subcategories: perinatal, injectable drug user (IDU), male homosexual/bisexual, blood transmission (blood transfusion recipients, including hemophiliacs), heterosexual, and other unknown means, according to the hierarchy established by UNAIDS with respect to the presumed means of transmission [16].

With the objective of investigating possible differences in the evolutive pattern of the epidemic according to socioeconomic level, the incident rates of AIDS were analyzed in individuals 20 to 69 years of age living in the three areas studied in this trial, according to gender and education level; the latter was used as the variable indicative of socioeconomic level. To permit comparison over time, rates were calculated for the years 1992 and 1999. Two education levels were considered: the first level included illiterates and those with 8 years of primary schooling, and the second included individuals who had completed high school and/or university. Those cases for which there was no information available regarding education level were proportionally distributed between the two groups. For the denominators of incidence rates, data on education level, calculated using the National Household Sampling Study (Pesquisa Nacional de Amostra por Domicílio - PNAD) for the years of 1992 and 1999, were considered, the variable being the years of schooling of all residents in the region.

Comparative analysis of the incidence of AIDS and the annual mortality was carried out using a study on the temporal evolution of patients aged 15 years or older and deaths from AIDS in the same age group, occurring in the year following diagnosis. In the mortality registers (SIM), the cause of death is registered according to the $9^{\text {th }}$ and $10^{\text {th }}$ Revisions of the International Classification of Diseases (ICD). All the registers of deaths of individuals of 15 years of age or more that occurred between 1991 and 2000, and which had registered AIDS as the basic cause of death, were included. The code 279.1 of the $9^{\text {th }}$ Revision of the ICD was used for the years 1991 to 1995 , and the codes B20 to B24 in the $10^{\text {th }}$ Revision were used for the years from 1996 to 2000.

For the analysis of the temporal trend of cases resulting from vertical transmission, cases occurring during the period 1990 to 1997 were considered, according to year of birth. Exponential regression models, adjusted to the temporal series in the years 1990 to 1996 , permitted calculation of the annual variation rates and were used to statistically test the temporal trends, as well as to estimate the expected values for the whole period, making it possible to compare the observed and expected values for children born in 1997.

\section{Results}

The analysis of the incidence rates of cases of AIDS in adults showed distinct trends when data from the northeast of the country were compared with data from Brazil as a whole or from the state of São Paulo (Figure 1 and Table 1). With respect to the total number of cases in Brazil, a relative increase in new cases was seen from 1990 onwards, with a tendency to stabilize from 1996 onwards and a reduction in the incidence in 1999. In São Paulo, the Brazilian state that registers the greatest number of cases of AIDS, with around $50 \%$ of all notified cases in the country, a similar phenomenon was observed to that seen for the country as a whole, except for a fall in rates that began in 1998. In the northeast of the country, where rates are lower than those of São Paulo, a trend towards growth has been seen over the entire period analyzed, with a 
discreet reduction in the incidence in the last year of the series.

Figure 1 and Table 1 show the differences in the temporal behavior of incidence rates according to gender. When the variations in the years included in the analysis are compared, it can be seen that the greatest relative increases occurred among women in all regions considered in the study, although the most expressive was in the northeast of the country. With respect to males, the epidemic has already been showing signs of deceleration since 1996 in Brazil as a whole and in the state of São Paulo. The same cannot be said for the northeast of the country, where the epidemic also continues to grow among the male population, except for a slight deceleration in 1999.

The distribution of AIDS cases to the subcategories of exposure in the areas studied revealed distinct regional patterns (Figure 2). The northeast of the country was characterized by the predominance of sexual transmission, which corresponded to $80 \%$ of the cases. Only a small proportion of cases were registered in the subcategory of IDU. On the other hand, in São Paulo and in the country as a whole, the percentage of cases in the IDU subcategory was similar to the percentage of cases in the heterosexual subcategory, and this group played an important role in the dissemination of the epidemic. In these areas, the percentage of cases in the sexual subcategories of male homosexual/bisexual or heterosexual was less than $50 \%$ in 1990 , and in the last year of the study it was around $60 \%$.

For the analysis of temporal variation in education level, AIDS patients aged 20-69, diagnosed between 1992 and 1999, were included, according to area of residence and gender. The results presented in Table 1 show a similar growth trend in cases with low educational levels compared to the total number of cases in all regions. However, the growth observed in the northeast of the country is clearly greater than that of the other areas in the study, and the lowest trend of reduction in the coefficient in cases with higher education levels was also registered in this area.

The differences between the southeast and the northeast of the country are the most striking when the distribution of cases is analyzed by gender. For males, results are similar to the total number of cases, with a clear growth trend in the incidence of cases with low education levels in all areas studied, and a greater increase in the northeast of the country.

For females, the incidence rates of AIDS in populations with higher education levels were the lowest from the beginning of the epidemic, and almost no differences were observed in the incidence of cases of this education level in the different areas studied. With respect to cases with the lower level of education, incidence rates were similar to those found for males and there was growth in all regions; however, the northeast region of the country registered the greatest variations, the proportion of growth in the incidence rates between 1992 and 1999 being $123 \%$ for males and $405 \%$ for females.

Comparative analysis of the incidence of AIDS and of mortality resulting from AIDS for the years 1990 to 1999, carried out by studying the temporal evolution of cases $>15$ years of age and of deaths from AIDS in the same age group occurring in the year following diagnosis, showed a constant, uniform, coincident growth up to 1995 in the number of cases and deaths due to AIDS in the different regions studied. From 1996 onwards, the increase in AIDS cases was not accompanied by an increase in deaths in any of the regions studied, and a progressive reduction in the number of deaths was observed (Figure 3). The pattern found in the state of São Paulo, however, appears to show that from 1997 onwards, there was also a reduction in the number of cases.

With respect to the analysis of the temporal trend of vertical transmission (Table 2), considering cases by year of birth during the period 1990 to 1996, all regions showed a significant increase. The greatest annual growth rate was in the northeast part of the country, with an approximate rate of $17 \%$, while the lowest was registered in São Paulo, with a rate below 5\%, showing clear signs of decrease. For Brazil as a whole, the annual growth rate was $12 \%$. It is worth noting, however, that according to the exponential regression models, in 1997 the expected number of cases of vertical transmission was consistently greater than the observed number of cases, principally in São Paulo and in the country as a whole. 
Table 1. Incidence rate (per 100,000 inhabitants) and the percentage of growth of AIDS cases, according to gender and education level, in northeast Brazil (NE), in São Paulo (SP) and in Brazil as a whole (BR), between 1992 and 1999

\begin{tabular}{|c|c|c|c|c|c|c|}
\hline \multirow[b]{3}{*}{ Region/Education level } & \multicolumn{6}{|c|}{ Incidence Rate } \\
\hline & \multicolumn{3}{|c|}{ Males } & \multicolumn{3}{|c|}{ Females } \\
\hline & 1992 & 1999 & $\%$ Increase & 1992 & 1999 & $\%$ Increase \\
\hline \multicolumn{7}{|l|}{$\mathrm{NE}$} \\
\hline Primary Education* & 6.27 & 13.98 & 123.08 & 1.30 & 6.57 & 404.96 \\
\hline Higher Education ${ }^{* *}$ & 21.79 & 18.33 & -15.88 & 2.62 & 3.92 & 49.50 \\
\hline \multicolumn{7}{|l|}{ SP } \\
\hline Primary Education* & 77.17 & 84.44 & 9.41 & 19.29 & 40.85 & 111.71 \\
\hline Higher Education ${ }^{* *}$ & 51.16 & 23.76 & -53.56 & 8.97 & 9.00 & 0.24 \\
\hline \multicolumn{7}{|l|}{$\mathrm{BR}$} \\
\hline Primary Education* & 28.48 & 39.62 & 39.15 & 7.10 & 20.55 & 189.46 \\
\hline Higher Education** & 33.92 & 21.70 & -36.02 & 5.44 & 7.27 & 33.74 \\
\hline
\end{tabular}

*up to 8 years of primary school; includes illiterates; ** high school or university.

Table 2. Observed number of AIDS cases acquired through vertical transmission and expected number by exponential regression model according to year of birth, in Brazil, São Paulo and the northeast Brazil, 1990 to 1996

\begin{tabular}{|c|c|c|c|c|c|c|}
\hline \multirow[b]{2}{*}{ Year of birth } & \multicolumn{6}{|c|}{ Region of residence } \\
\hline & \multicolumn{2}{|c|}{$\begin{array}{c}\text { Brazil }^{\mathrm{a}} \\
\text { Observed }^{\mathrm{d}} \text { Expected }^{-}\end{array}$} & \multicolumn{2}{|c|}{$\begin{array}{c}\text { São Paulo } \\
\text { Observed }^{\mathrm{d}} \text { Expected }^{\text {Expecte }}\end{array}$} & \multicolumn{2}{|c|}{$\begin{array}{c}\text { Northeast }^{\mathrm{c}} \\
\text { Observed }^{\mathrm{d}} \text { Expected }^{\text {Expect }}\end{array}$} \\
\hline 1990 & 393 & 439 & 219 & 246 & 19 & 20 \\
\hline 1991 & 543 & 489 & 290 & 258 & 29 & 24 \\
\hline 1992 & 529 & 546 & 267 & 270 & 22 & 28 \\
\hline 1993 & 666 & 609 & 300 & 283 & 40 & 33 \\
\hline 1994 & 665 & 679 & 285 & 296 & 36 & 38 \\
\hline 1995 & 788 & 758 & 331 & 310 & 42 & 45 \\
\hline 1996 & 789 & 846 & 301 & 324 & 54 & 52 \\
\hline 1997 & 557 & 944 & 199 & 340 & 43 & 61 \\
\hline
\end{tabular}

Rates of annual variation: $\left({ }^{\mathrm{a}}\right) 0.115(\mathrm{p}=0.001) ;\left(^{\mathrm{b}}\right) 0.047(\mathrm{p}=0.047) ;\left(^{\mathrm{c}}\right) 0.169(\mathrm{p}=0.005)$. ${ }^{\mathrm{d}}$ Source: SINAN, Ministry of Health, December 2002. 
Figure 1. Incidence rate (per 100,000 inhabitants) of AIDS cases in adults, according to gender and year of diagnosis, in northeast Brazil (NE), in São Paulo (SP) and in Brazil as a whole (BR) between 1990 and 1999.
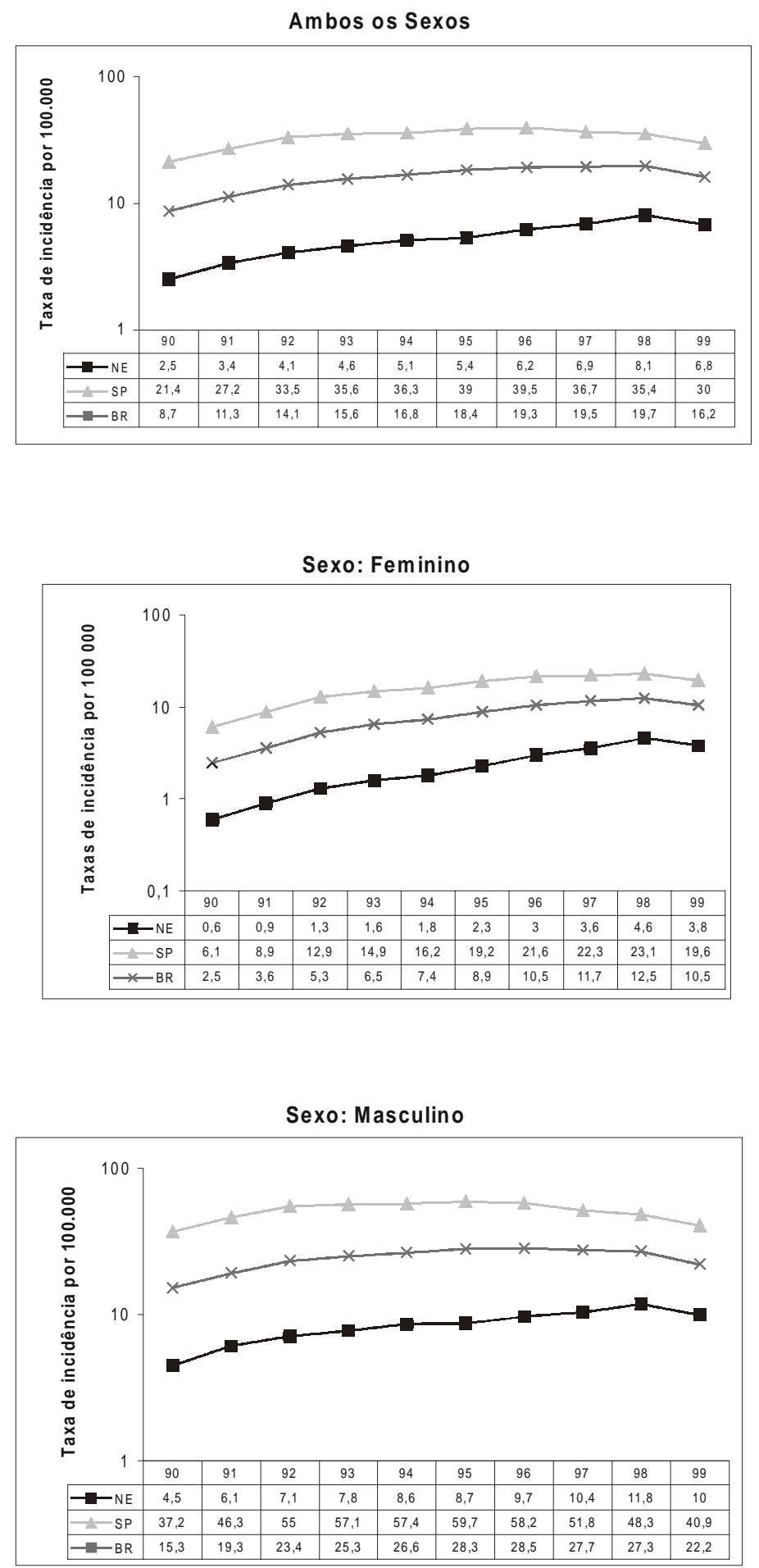
Figure 2. Proportion of cases of AIDS by year of diagnosis and subcategory of exposure in the northeast, in São Paulo and in Brazil from 1990 to 1999.
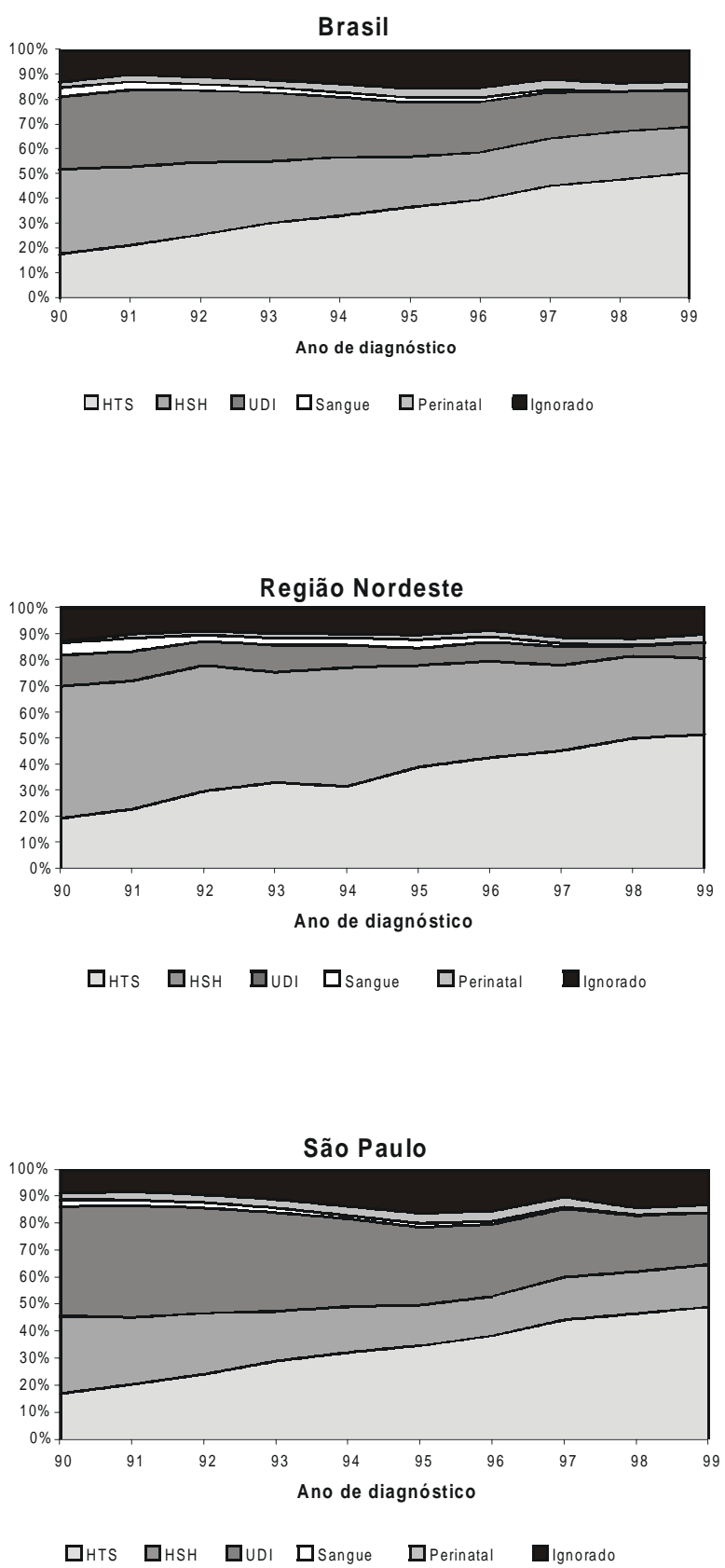
Figure 3. Number of cases of AIDS* and of deaths** in persons $=15$ years of age in the northeast, in São Paulo and in Brazil from 1990 to 1999.

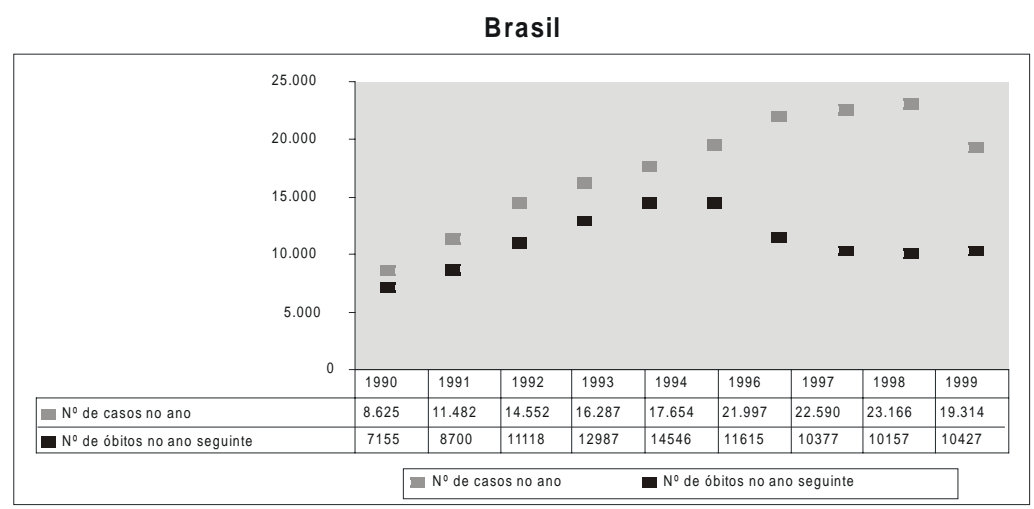

Região Nordeste

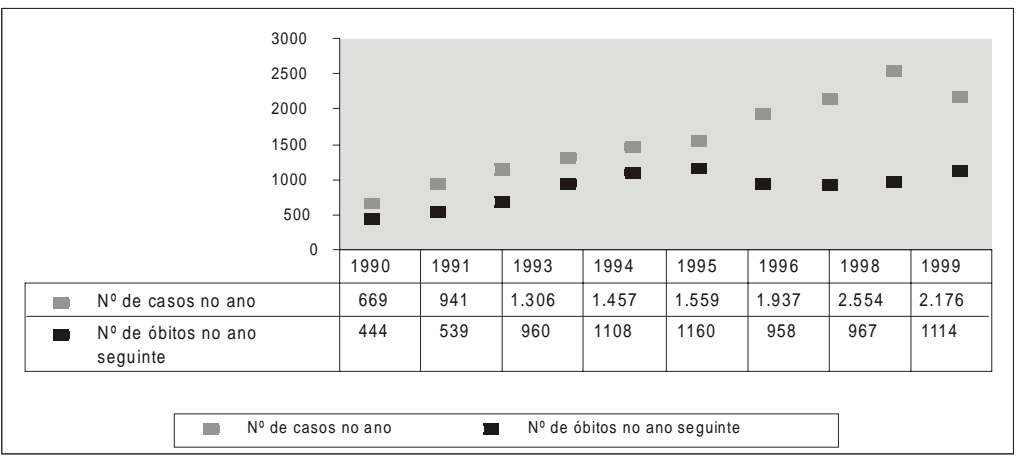

São Paulo

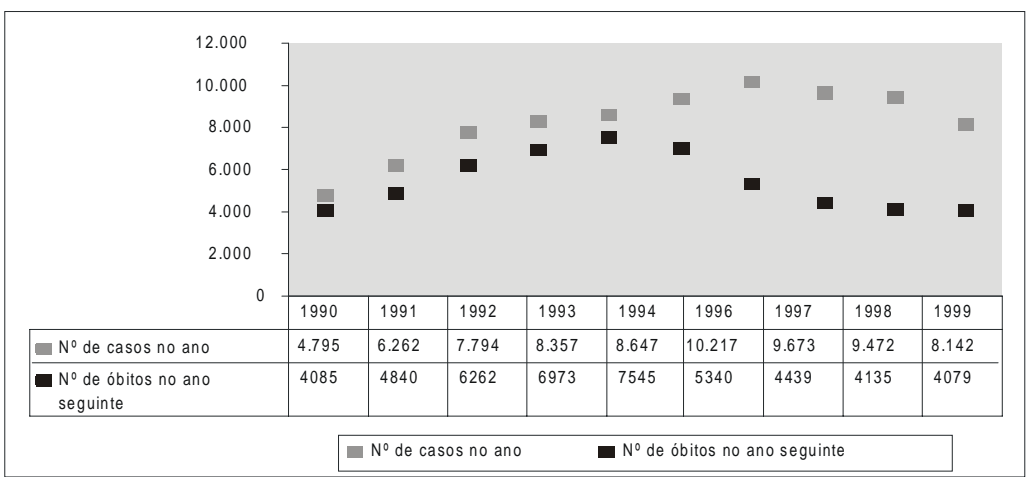




\section{Discussion}

We investigated the temporal changes in the AIDS epidemic in Brazil and found a trend towards stable incidence rates, particularly since 1996, coinciding with the introduction of potent ARV therapy for the treatment of AIDS victims, as has also been seen in other parts of the world. It is important to emphasize that this deceleration of the epidemic did not occur homogeneously in all the regions studied. The trend towards stabilization and deceleration was seen principally in São Paulo and in Brazil as a whole, while in the northeast of the country the data does not indicate stabilization.

In an attempt to explain the current trend of the epidemic in the northeast of the country, some nonexcluding hypotheses may be raised. One is the fact that the virus was introduced later to those regions farther from the epicenter of the epidemic in Brazil, the states of Rio de Janeiro and São Paulo in the southeast part of the country [16], where there is a great number of susceptible people. Another hypothesis is a result of the limitations imposed by the centralization and lack of coverage of the preventive measures and healthcare in the northeast part of the country, still largely concentrated in the capital cities and in a few of the largermunicipalities, in contrast with the tendency of dissemination of the epidemic in the smaller towns, particularly due to transmission among the heterosexual population [17].

This fact is explained by the different possibilities of access to material goods and services, resulting in unsatisfactory healthcare for a large percentage of patients and delayed or inadequate access to diagnostic and therapeutic measures, particularly to ARV therapy [18]. Similarly, with respect to preventive measures, male adolescents living in the north or northeast have the highest-risk sexual practices, compared to adolescents living in other regions of the country [19].

Despite the limitations of the use of education level as a variable representative of socioeconomic condition, this was the only variable consistently available from SINAN, other than "occupation", which was indicative of this condition; the results consistently show that the AIDS epidemic in the country began in the population with the highest education level, consequently disseminating to groups of lower education level. This finding was observed in all the regions studied, in both sexes, and corroborates the aforementioned hypothesis regarding the iniquities of access to health care.

The fact that the risk to which women of greater educational level in all regions of the country are exposed has remained practically unchanged throughout the progression of the epidemic is noteworthy. On the other hand, the risk of AIDS is growing progressively among women of lower educational level, most markedly among women in the northeast of the country, indicating a clear tendency of the epidemic to "pauperize", particularly among women. This finding is in agreement with previous studies carried out in the country [17-20].

The comparative analysis of the incidence of AIDS with the annual mortality shows changes in the morbidity/mortality of AIDS similar to those seen in other countries [10,21,22]. Data show a decrease in the incidence of cases and of deaths from AIDS that coincides with the introduction of potent ARV therapy in the country. Even in the northeast of the country, with respect to the increase in the incidence of cases that was registered until recently, it is possible to observe a decline in mortality, suggesting that the universal character of ARV therapy may also have an impact on the reduction in the socioeconomic inequalities of the dissemination of the epidemic that is currently seen.

In our study, during the period 1990 to 1996 , clear increases were seen in the number of cases of vertical transmission, particularly in the northeast, where the annual growth rate was $17 \%$. Results on the comparison of the number of observed cases and the number of expected cases in 1997, following adjustment for the exponential regressions to the data in the period 1990 to 1996, are more encouraging. The number of cases observed in São Paulo, and in Brazil as a whole, was much fewer than expected for those born in 1997 , suggesting a favorable response to the implementation of intervention policies in the prevention of the vertical transmission of HIV, as has occurred in other parts of the world [23]. 
On the other hand, the pattern seen in the northeast of the country, with fluctuations in the difference between the number of observed cases and the number of expected cases during the study period, may indicate problems of under-notification of cases of vertical transmission, due to the low quality of prenatal and obstetrical care, as well as the difficulties in carrying out diagnosis of HIV infection in pregnant women and newborn infants in this region. In agreement with this hypothesis, a recent study on congenital syphilis carried out in the prenatal clinics of five maternity hospitals in the city of Recife [24] showed that $84.4 \%$ of the pregnant women whose newborn infants had been diagnosed with congenital syphilis, had attended at least four prenatal consultations, suggesting a low quality of healthcare offered to pregnant women during the prenatal period and delivery, despite the wide coverage of these services. On the other hand, the possibility cannot be discarded that an increase in the number of cases observed in the northeast of the country may be a consequence of an improvement in the system of notification.

The prevention policy for the vertical transmission of HIV in Brazil includes the introduction in 1995 of antiretroviral therapy for prophylaxis and/or treatment of the pregnant women infected with HIV or with AIDS, and their children [23]. With respect to the difficulty in obtaining data to monitor the various stages of implementing these interventions, our study has shown that the temporal trend analysis of notified cases of AIDS resulting from vertical transmission might help in the evaluation of the impact of these measures.

\section{References}

1. Fauci A.S. The human immunodeficiency virus: infectivity and mechanisms of pathogenesis. Science 1988;239:617-22.

2. Alen O.O., Farewell V.T., De Angelis D. New therapy explains the fall in AIDS incidence with a substantial rise in number of persons on treatment expected. AIDS 1999;13:103-8.

3. Brodt H.R., Kamps B.S., Gute P., et al. Changing incidence of AIDS-defining illnesses in the era of antiretroviral combination therapy. AIDS 1997;11:1731-8.
4. Holodniy M. Editorial response- What is antiretroviral failure? Clin Infect Dis 1999;29:82-4.

5. Pezzotti P., Napoli P.A., Acciai S. Increasing survival time after AIDS in Italy: the role of new combination antiretroviral therapies. AIDS 1999;13:249-55.

6. Centers for Disease Control and Prevention (CDC). Decrease in AIDS - Related Mortality in a State Correctional System - New York, 1995-1998. MMWR 1999;47:1115-7.

7. Egger M., May M., Chêne G., Phillips N.A., et al. Art Cohort Collaboration. Prognosis of HIV-1 - infected patients starting highly active antiretroviral therapy: a collaborative analysis of prospective studies. Lancet 2002;360:119-29.

8. Fleming P.L., Ward J.W., Karon J.M. Declines in AIDS incidence and deaths in the USA: a signal change in the epidemic. AIDS 1998; 12 Suppl A:S55-61.

9. Lee M.L., Karon J.M., Selik R., et al. Survival after AIDS diagnosis in adolescents and adults during the treatment era, United States, 1984-1997. JAMA 2001;285: 1308-15.

10. Mocroft A., Brettle R., Kirk O., et al. Changes in the cause of death among HIV positive subjects across Europe: results from the EuroSIDA study. AIDS 2002; 16:1663-71.

11. Tassie J.M., Grabar S., Lancar R., et al. Time to AIDS from 1992 to 1999 in HIV-1 infected subjects with known date of infection. Journal of acquired immune deficiency syndrome human retroviral 2002;32:1487-93.

12. Coordenação Nacional de Doenças Sexualmente Transmissíveis e AIDS (CNDST/AIDS). Terapia Antiretroviral e Saúde Pública: Um balanço da experiência brasileira. Brasília: Ministério da Saúde, 1999.

13. Levi G.C., Vitória M.A.A. Fighting against AIDS: the Brazilian experience. AIDS 2002;16:2373-83.

14. Coordenação Nacional de Doenças Sexualmente Transmissíveis e AIDS (CNDST/AIDS). Estratégia de mercado: compromisso com a vida. Market strategy: a commitment to life. In: Resposta positiva: A experiência do programa brasileiro de AIDS. Brasília: Ministério da Saúde, 2002.

15. Marins J.R., Jamal L.F., Chen S., et al. Sobrevivência atual dos pacientes com aids no Brasil. Evidência dos resultados de um esforço nacional. Boletim Epidemiológico - AIDS, Ministério da Saúde 2002; XV(1),SE outubro 2001/março 2002.

16. Szwarcwald C.L., Bastos F.I., Esteves M.A., Andrade C.L.T. A disseminação da epidemia da aids no Brasil, no período de 1987-1996: uma análise espacial. Cad Saude Publica 2000;16 Sup1:S7-19.

17. Brito A.M., Castilho E.A., Szwarcwald C.L. AIDS e infecção pelo HIV no Brasil: uma epidemia multifacetada. Rev Soc Bras Med Trop 2001;34:207-17. 
18. Brito A.M. Os múltiplos perfis da epidemia da aids e a era dos anti-retrovirais no Brasil. Tese (Doutorado), 2003; Escola Nacional de Saúde Pública, Fundação Oswaldo Cruz.

19. Szwarcwald C.L. Avaliação dos conscritos do exército. Brasília: Ministério da Saúde, 1997.

20. Fonseca, M.G., Bastos, F.I., Derrico, M., et al. AIDS e grau de escolaridade no Brasil: evolução temporal de 1986 a 1996. Cad Saude Publica 2000, vol.16, suppl.1, p.77-87.

21. Chiasson M.A., Berenson L., Li W., et al. Declining HIV/ AIDS mortality in New York City. Journal of acquired immune deficiency syndrome human retroviral 1999;21:59-64.

22. Palella F.J., Delaney K.M., Moorman A.C., et al. Declining morbidity and mortality among patients with advanced Human Immunodeficiency Virus infection. HIV Outpatient Study Investigators. N Engl J Med 1998;338:853-60.

23. Veloso V.G., Vasconcelos A.L., Grinsztejn B. Prevenção da transmissão vertical no Brasil. Boletim Epidemiológico - AIDS, Ministério da Saúde 1999;XII(4),SE 23-35, junho/agosto.

24. Brito A.M., Silva A.E.M., Acioli Neto J.A., et al. Sífilis congênita na cidade do Recife: um marcador da qualidade do serviço de pré-natal. Revista da Sociedade Brasileira de Doenças Sexualmente Transmissíveis 2002;14:116-7. 